\title{
Excess Fibrin Deposits Decrease Fetal Weight of Pregnant Mice Infected by Plasmodium berghei
}

\author{
Desy Andari ${ }^{1 *}$, Zainabur Rahma ${ }^{2}$, Yuliyanik ${ }^{3}$, Sujarot Dwi Sasmito ${ }^{4}$, Karyono Mintaroem ${ }^{5}$, Loeki Enggar Fitri ${ }^{6}$ \\ ${ }^{1}$ Departement of Histology, Faculty of Medicine, Muhamadiyah University, Malang, Indonesia. \\ ${ }^{2}$ Doctoral Program in Medical Science, Faculty of Medicine, Brawijaya University, Malang, Indonesia \\ ${ }^{3}$ Widyagama Husada Health Science High School Malang, Indonesia \\ ${ }^{4}$ Master Program in Biomedical Science, Faculty of Medicine, Brawijaya University, Malang, Indonesia \\ ${ }^{5}$ Departement of Pathology, Faculty of Medicine, Brawijaya University, Malang, Indonesia \\ ${ }^{6}$ Departement of Parasitology, Faculty of Medicine, Brawijaya University, Malang, Indonesia
}

\begin{abstract}
Low birth weight is commonly attributed to malaria in pregnancy, but the cellular and molecular mechanisms that underlie this poor birth outcome are incompletely understood. A universally described histopathological feature of placental malaria is excessive deposition of fibrin, the end-product of the coagulation cascade. This study was conducted to compare fibrin deposit in pregnant mice that infected by Plasmodium berghei (treatment group) to the normal pregnant mice (control group) and its association with fetal weight. This research is in vivo experimental laboratory study that used 18 pregnant $\mathrm{Balb} / \mathrm{c}$ mice which divided to the control the group (8 mice) and treatment group (9 mice infected by P.berghei). Placentas were staining with Haematoxylin-Eosin (HE) for fibrin deposits examination whereas fetal weight was performed with Mettler analytical balance AE 50. Fetal weight of the treatment group was lower than those of the control group ( test, $\mathrm{p}=0,002)$. Fibrin deposits were increased in the treatment group ( $\mathrm{t}$ test, $\mathrm{p}=0,005)$ and influenced weight of fetuses (Spearman $\mathrm{r}=$ $0,586, p=0,014)$. Weights of fetuses are interfered by fibrin deposits during malaria infection.
\end{abstract}

Keywords: malaria, pregnancy, fibrin deposit

\section{INTRODUCTION}

The Millenium Development Goals (MDG's) global commitments are included controlling and eliminating malaria by 2015 [1]. According to Annual Parasite Incidence, some areas in Indonesia are still in high level of malaria and the other areas are in moderate and low level [2]. Individuals in all continents are potentially in risk, but the greatest suffering falls to people in tropical countries with newborns, children less than five years of ages and pregnant women are vulnerable group for this disease. Pregnant women, even if previously clinically immune, have a significant enhanced risk for a pathogenic

\footnotetext{
*Corresponding author:

Desy Andari

Departement of Histology, Faculty of Medicine

Universitas Muhamadiyah, Malang

E-mail: desy.qruezt@gmail.com
}

pregnancy [3]. Malaria in pregnant women could cause anemia to the mother. There was an association between severe anemia and malaria, but there were no significant differences from primigravidae to multigravidae [4]. Malaria in pregnant women could also cause morbidity in fetus like low birth weight [5], preterm delivery and died after birth [6].

Malaria in pregnancy has a particular feature that is the accumulation of infected red blood cells within the placenta [7] which is referred as placental malaria. Placental malaria revealed a number of abnormalities to placental tissue such as excess of fibrinoid deposits and malarial pigment deposits (haemozoin) [8].

To further investigate the association between the fibrin deposits and fetal weight, we conducted an experimental study to analyze the histopathological change in placenta (fibrin deposit and weight of the fetus in pregnant mice that infected with Plasmodium berghei. 


\section{MATERIALS AND METHODS}

\section{Research design and samples}

This experimental study was conducted using fifty adult female BALB/c mice with 13-15 weeks old and 20-30 grams weight. In order to get a group of pregnant mice with the same gestation, the mice then been synchronized their oestrus cycles using Leebot, Pheromone and Whitten effects and then mated simultaneously in pair within one night. They were then divided into two groups and observed daily. On the ninth day post mating (estimated to be the second trimester of pregnancy), the study group were infected by Plasmodium berghei.

On the 18th days post mating (estimated to be the third trimester of pregnancy), the mice were killed humanely by placing them into plastic cage containing cotton wool soaked with chloroform. Surgery was performed immediately to isolate the placenta and the fetus. The fetus was weighed individually, and the placentas were isolated and store in $10 \%$ formaldehyde.

\section{Ethical considerations}

Ethical clearance was provided by the committees of research of the Medical Faculty Universitas Brawijaya (No. 104/EC/KEPKS2/03/2013). All animals were treated well during this research and buried after research.

\section{Animals and parasites}

The $\mathrm{BALB} / \mathrm{c}$ mice were obtained from Universitas Gadjah Mada and maintained in conventional housing at the Parasitology Laboratory Faculty of Medicine Universitas Brawijaya. Infection experiments were performed in adult females, between 13-16 weeks of age. Parasitology Laboratory Universitas Brawijaya provided Plasmodium berghei anka. All animals were fed with regular diet, and all procedures were in accordance with national regulations on animal experimentation and welfare.

\section{Preparations and inoculation of $P$. berghei}

The Plasmodium berghei ANKA was revived from the storage of liquid nitrogen tank $-135^{\circ} \mathrm{C}$, then centrifuged at $2000 \mathrm{rpm}$ for 5 minutes, and washed twice in RPMI medium and diluted as needed for inoculation intraperitoneally (ip) as much as $10^{7}$ parasites in $0.2 \mathrm{ml}$ of blood per mice. The degrees of parasitemia were measured by examining slides of thin blood smear taken from the end of mouse tails and stained with Giemsa under light microscope with 1000x magnification, and counting the number of infected erythrocytes per 1000 erythrocytes by three different observers.

\section{Pregnancy experimental infection and isolation of the placenta and the fetus}

Pregnant mice were intraperitoneally infected at day - 9 pregnancy with $10^{6} \mathrm{iRBC}$, and parasitemia was recorded every other day. Non-infected pregnant females were used as controls in pregnancy infection experiments as appropriate. Part of the pregnant females (both infected and controls) were caesarian section at day-18 of pregnancy to placenta pathology observation and the fetus were scaled using analytical scale (Mettler AE 50).

\section{Tissue preparation and histopathological analysis}

Placentas from infected and non-infected females were treated in a similar way. Placentas were fixed in formaldehyde for further tissue processing (sectioning). Paraffin-embedded nonconsecutive placenta sections were stained with Haematoxylin-Eosin (HE) and examined under a light microscope (Olympus CX 21 LED FSI).

\section{Measurements of fibrin deposit and fetal weight}

Placental sections were stained with $\mathrm{H}-\mathrm{E}$ and examined under light microscope under supervised of Anatomical Pathologist. All sections were approached in a blinded manner and initially assessed

\section{Statistical analysis}

Analyzes were performed using SPSS 16 software. Statistical differences between groups of mice used in this study were evaluated by t test for normally distributed data. Correlation test was done using Spearman. Analyzes were performed using SPSS 16 software. Statistical differences between groups of mice used in this study were evaluated by $t$ test for normally distributed data. Correlation test was done using Spearman. 


\section{RESULTS AND DISCUSSION}

\section{Fibrin deposits}

Assessment of histological sections for placental fibrin revealed that the treatment group had more deposition than the control group and the difference is significant (independent $t$ test $\mathrm{p}<0,005)$ (Table 1, Figure 1).

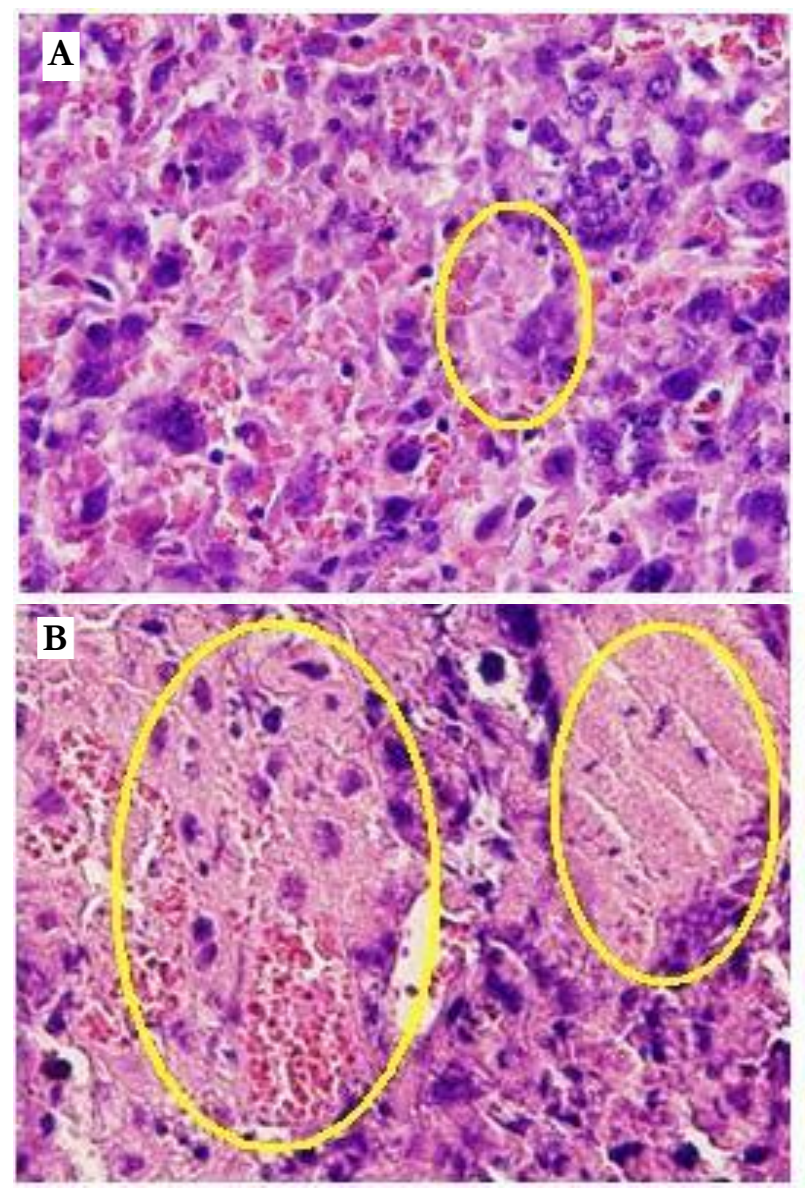

Figure 1. Fibrin deposits in placenta. Treatment group (B) shows excessive area of fibrin deposits (yellow circle) than the control group (A). (HE, $400 \mathrm{x}$ magnification).

\section{Fetal weight}

Mean fetal weight in this study was $0,9392 \mathrm{~g}$ for the control group and $0,6480 \mathrm{~g}$ for the treatment group. Using independent $t$ test there was a significant differences $(p=0,002)$ whixh can be seen in Figure 2.

\section{Correlation Test between Fibrin Deposit and Fetal Weight}

There was a negative moderate correlation between fibrin deposit and fetal weight (Spearman $=-0,586, \mathrm{p}=0,014)$ and significant. Table 2 shows the data.

Table 1. Fibrin deposition in treatment and control group.

\begin{tabular}{cccc}
\hline & \multicolumn{2}{c}{$\begin{array}{c}\text { Fibrin } \\
\text { deposition }\end{array}$} & \\
\cline { 2 - 3 } No & Control & Treatment & $\begin{array}{c}\text { Independent t } \\
\text { test }\end{array}$ \\
\hline 1 & 1 & 2 & \\
2 & 2 & 2 & \\
3 & 1 & 2 & \\
4 & 1 & 1 & \\
5 & 1 & 2 & \\
6 & 1 & 2 & \\
7 & 2 & 2 & \\
8 & 1 & 2 & \\
9 & & 2 & \\
Mean & 1,250 & 1,889 & 0,005 \\
\hline
\end{tabular}

Note : 1= Fibrin deposition $<=30 \%, 2=$ Fibrin deposition $>30 \%$.

Fibrin deposit in the treatment group was significantly increasing than the control group in this study. This finding was supported by [9] that histological sections for placental fibrin revealed that women with placental malaria had more deposition than normal pregnant women, although the difference was subtle. Placental malaria induces dysregulated hemostasis both active coagulation and suppressed fibrinolysis and thus provided an expanded functional explanation for the excessive fibrin accumulation found in the infected placenta [9].

Weight of fetuses was significantly different between the control group and treatment group, this was supported by many previous studies [6, 9, 10]. The means of birth weight, chest circumference, ponder index, and placental weight were significantly lower among the babies of mothers with malaria-infected placenta than those without. They also suggested that parity and presence of malaria have independent significant roles in the etiology of fetal malnutrition, and also in turn, have effects on the anthropometric data of the babies affected [10]

This study showed a significant negative moderate correlation between fibrin deposit and 
fetal weight. It means an increase of fibrin deposit in placenta will also increase the risk of fetal weight reduction. The data is supported by [9] that concluded infants born to infected women with elevated placental fibrin deposition did have reduced mean birth weights relative to uninfected cases with low fibrin. Evidence for a pathogenic role of dysregulated hemostasis in placental malaria will require coupling of functional coagulation metrics with identification of specifically pathological outcomes, such as placental fibrin deposition, associated placental damage, premature birth and/or fetal growth restriction [9].

Deposition of fibrin material is seen virtually in every placenta with the amount of deposited fibrin material increasing the closer the pregnancy reaches term. According to [11], the placenta can withstand the loss of up to $30 \%$ of adverse effects. However, extensive per villous fibrin deposition is a distinctly pathologic condition associated with fetal growth restriction, intrauterine fetal demise, neonatal morbidity, and high recurrence risk in subsequent gestation [11].

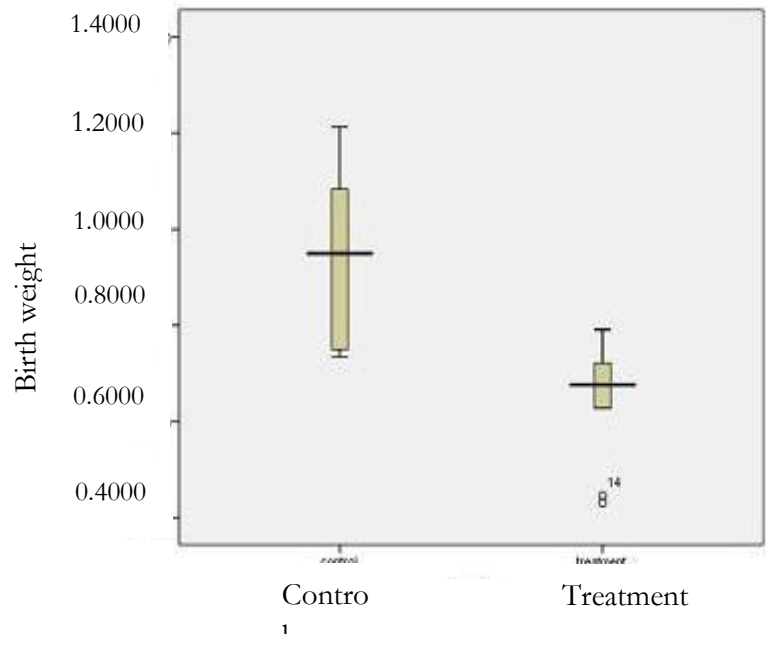

Figure 2. Fetal weight of control and treatment group

Increasing of fibrin deposition in placenta is leading to necrosis. Massive chronic intervillositis could cause this. The lesion can occur in any gestational age and reportedly the highest recurrence risk of the placental pathologies and may include intrauterine growth restriction and fetal death in utero [12].

Table 2. Correlation between fibrin deposit and fetal weight.

\begin{tabular}{llll}
\hline Fibrin Deposition & & \\
\hline Spearman's rho & Fetal Body & Correlation Coefficient & -.586 \\
& Weight & Sig. (2-tailed) & .014 \\
& $\mathrm{~N}$ & 17 \\
\hline${ }^{*}$. Correlation is significant at the 0.05 level (2-tailed). & \\
\hline
\end{tabular}

\section{CONCLUSIONS}

Placental malaria alters placenta histology such as excess fibrin deposit and also reducing fetal weight.

\section{ACKNOWLEDGMENT}

The authors would like to thank Universitas Brawijaya, Malang, Indonesia for financial support for this project. We express our appreciation to our partners in study of placental malaria: Nur Fahma Pradiptasari, Adila Ulfiati, Bougenvil Ungu and the staff of the Parasitology
Laboratory Faculty of Medicine Universitas Brawijaya for the animal housing.

\section{REFERENCES}

1. WHO (2012) WHO Global Malaria Programme: World Malaria Report. http: // www. who.int/ malaria/publications/world_malaria_report_201 2 /en/

2. Kemenkes RI (2011) Buletin Malaria: Epidemiologi Malaria di Indonesia. Triwulan I. file:///C:/Users/lenovo/Downloads/buletinmalaria.pdf

3. Miller LH, Good MF, Milon G (1994) Malaria Pathogenesis. ProQuest. Science. 264: 1878-1883. 
4. Shulman CE, Marshall T, Dorman EK, Bulmer JN, Cutts F, Peshu N, Marsh K (2001) Malaria in pregnancy: adverse effects on haemoglobin levels and birthweight in primigravidae and multigravidae. Tropical Medicine and International Health. 6(10): $770-778$.

Menendez C, Ordi J, Ismail MR, Ventura PJ, Aponte JJ, Kahigwa E, Font F, Alonso PL (2000) The Impact of Placental Malaria on Gestational Age and Birth Weight. The Journal of Infectious Diseases 2000. 181: 1740-5.

5. Neres R, Marinho CRF, Goncalves LA, Catarino MB, Penha-Goncalves (2008) Pregnancy Outcome and Placenta Pathology in Plasmodium bergei ANKA Infected Mice Reproduce the Pathogenesis of Severe Malaria in Pregnant Women. PLoS ONE. 3(2): e1608.

6. Duffy PE and Fried M (2003) Plasmodium falciparum adhesion in the placenta. Curr. Opin. Microbiol. 6: 371-376.

7. Walter PR, Garin Y, Blot P (1982) Placental Pathologic Changes in Malaria: A Histologic and Ultra-structural Study. American Association of Pathologists. 109(3): 330-342.
8. Avery JW, Smith GM, Owino SO, Sarr D, Nagy T, Mwalimu S, Matthias J, Kelly LF, Poovassery JS, Middii JD, Abramowsky C, Moore JM (2012) Maternal Malaria Induces a Procoagulant and Antifibrinolytic State That Is Embryotoxic but Responsive to Anticoagulant Therapy. PLoS ONE. 7(2): e31090.

9. Adebami OJ, Owa JA, Oyedeji GA., Oyelami OA, Omoniyi-Esan GO (2007) Associations Between Placental and Cord Blood Malaria Infection and Fetal Malnutrition in an Area of Malaria Holoendemicity. Am. J. Trop. Med. Hyg. 77(2): 209-213.

10. Faye-Petersen OM, Heller DS, Joshi VV (2006) Handbook of Placental Pathology. Second Edition.

11. Roberts DJ (2008) Placental Patholgy, a Survival Guide. Arch Pathol Lab Med. 132(4): 642-651. 